Kantorowicz, O. (1951). J. gen. Microbiol. 5, 276-278.

\title{
Shaking Apparatus for the Aeration of Bacterial Cultures
}

\author{
By O. KANTOROWICZ \\ National Institute for Medical Research, Mill Hill, London N.W. 7
}

A large shaker designed to satisfy simultaneously and without mutual interference the conflicting demands of a team of bacteriologists, has been placed in one of this Institute's hot-rooms. The shaker runs at a constant speed of 100 shakes/min., but each user is free to select an amplitude of reciprocative motion to suit his requirements, by placing a loaded tray at a suitable distance from the centre of oscillation. This can be done without stopping the motion of the apparatus.

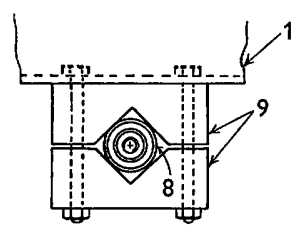

Fig. 2

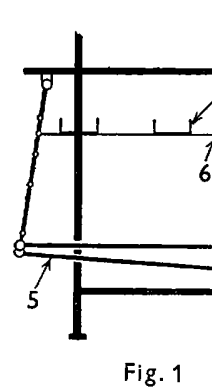

Fig. 1

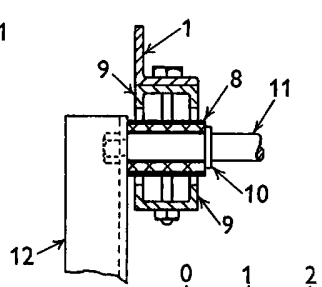

Fig. 3
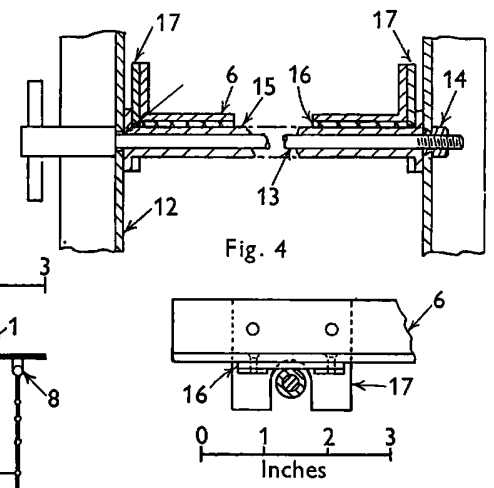

Fig. 5 SHAKING ADDARATUS

Third Angle Projection.

It consists of an aluminium alloy scaffolding (1) (Fig. 1, thick lines) and on to this are hinged two 'swings' (medium lines) which are driven at constant speed by means of a 1500 r.p.m. synchronous motor (2). This, through a 2-stage 'Vee' belt reduction gear (3), drives a two-throw crank (4) at 100 r.p.m. The crank pins are $90^{\circ}$ out of phase with each other and oscillate one swing each by means of long connecting rods (5). Loose bearer rails (6) can be attached to the swings at various distances from the upper hinge points and reciprocate therefore at various amplitudes (maximum \pm 2 in.). Small trays (7), loaded in the laboratories, can be placed securely on the bearer rails without stopping the machine.

Design details are illustrated by subsequent figures. Fig. 2 shows a typical 
hinge as used on the swings, and the swing end of the connecting rods. It consists essentially of a 'Silentblock', i.e. a rubber bush pressed in between two steel sleeves, the outer one being pinched by two 'Vee' notches in short pieces of aluminium alloy channel (9) and the inner one is screwed against a shoulder (10) on a bar (11). As may be seen more clearly in Fig. 3, the channels (9) are bolted to the scaffolding (1) and the bar carries the vertical members (12) of the swings.

Fig. 4 describes the method used in locating the bearer rails. Pins (13) are inserted into holes in the front vertical members (12) and screwed into 'Hank Bushes' (14) secured to the other vertical members.

Holes for pins (13) are provided at exponentially increasing distances from the upper hinge. The distance increases from hole to hole by $50 \%$ and, of course, the amplitudes of reciprocation are increasing correspondingly.

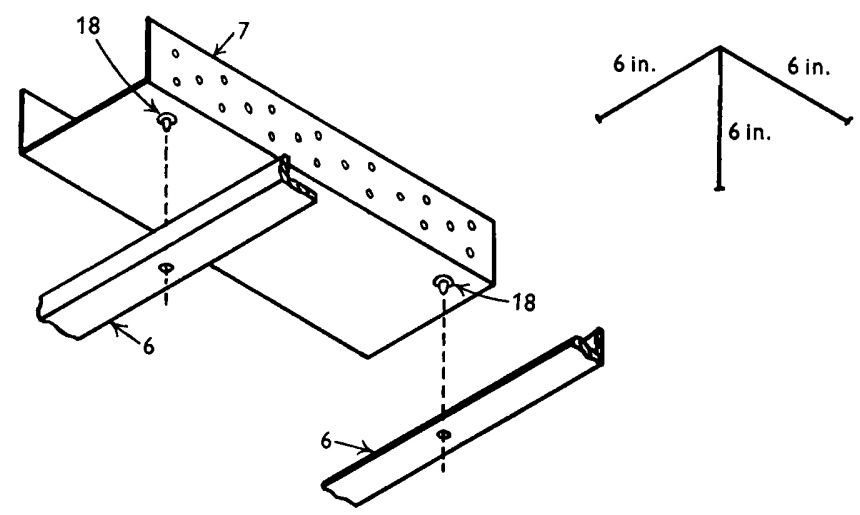

Fig. 6

Tubular spacers (15) are threaded on the pins (13), and the bearers (6) rest on these. (It was originally intended that 15 should rotate on 13 . This did not take place however. In future 15 will be omitted and 13 made correspondingly thicker.) A piece of rubber sheet (16) is secured to the underside of the bearer rail (6) and at one end check plates (17) are provided to prevent the bearer rail wandering off their supports. Rubber treads and check plates are seen better in Fig. 5.

Fig. 6 shows in isometric projection a typical tray (7) formed of (pure) aluminium sheet. This is equipped with two conical feet (18) by means of which it engages holes spaced 8 in. apart in the bearer rails (6). A great number of holes $\left(\frac{3}{8}\right.$ in. diameter) are provided in the sides of the trays. Rubber bands threaded through and secured by office paper-clips (Gem Clips) are used to secure bottles and flasks to the trays.

It was found that although a $\frac{1}{8}$ h.p. motor provided adequate torque, it became too hot at the prevailing temperature ( $37^{\circ}$ ambient) and a $\frac{1}{4}$ h.p. motor was substituted. The photograph (Pl. 1), shows the part of the apparatus represented diagrammatically by Fig. 1. In case of need a second pair of 
swings can be added above the part shown in a space occupied at present by (stationary) shelves. The apparatus is so free of noises that provided there is no jingle of caps the prevailing sound is the swish of the bottle contents.

The development owes much of its success to the skill and ingenuity of Mr Beadle and Mr Davey, respectively, the instrument-maker and the foreman in charge of the project.

(Received 7 June 1950) 
Journal of General Microbiology, Vol. 5, No. 2

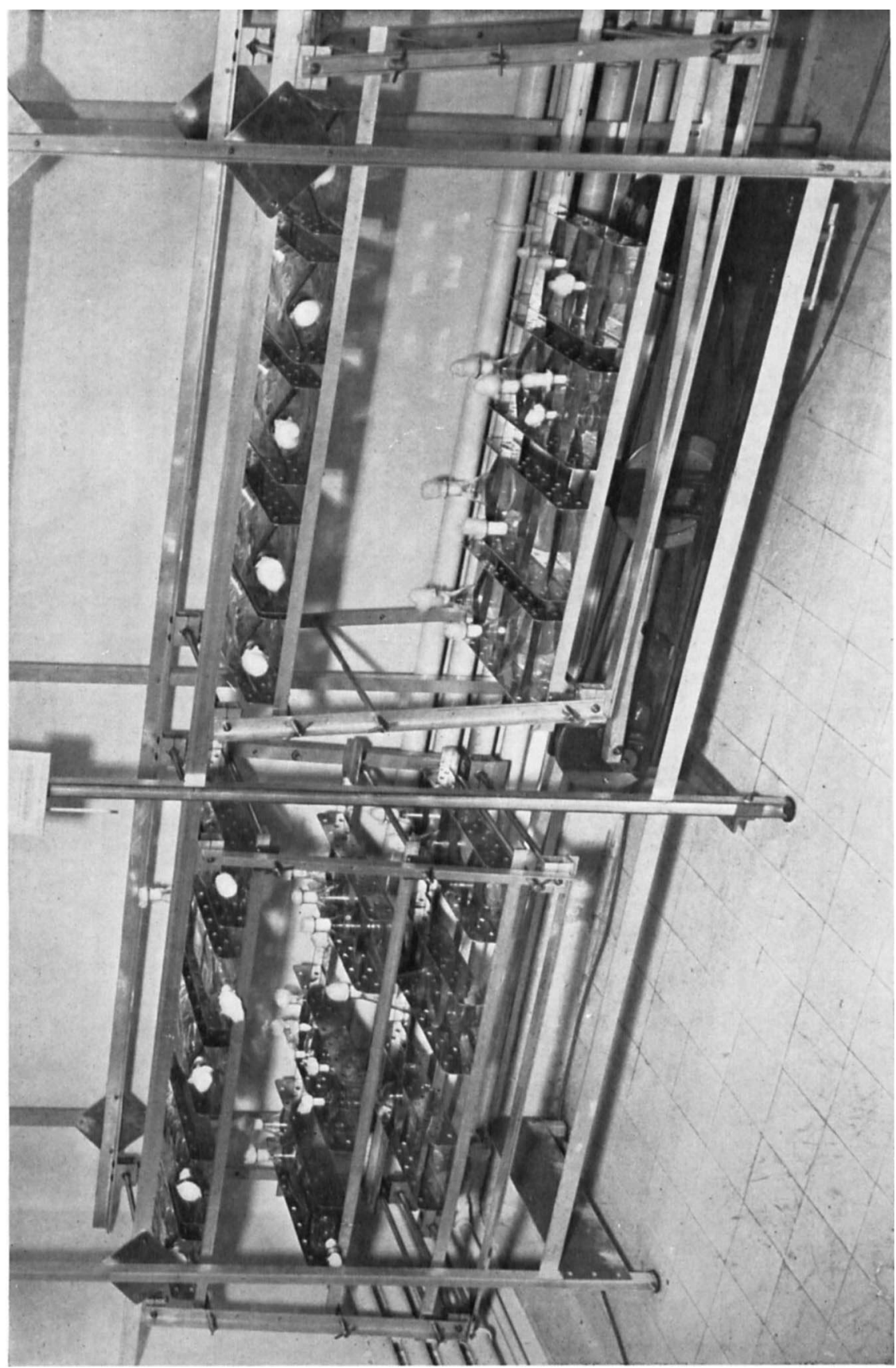

O. Kantorowitz-Shaking apparatus for bacterial cultures. Plate 1 
Journal of General Microbiology, Vol. 5, No. 2

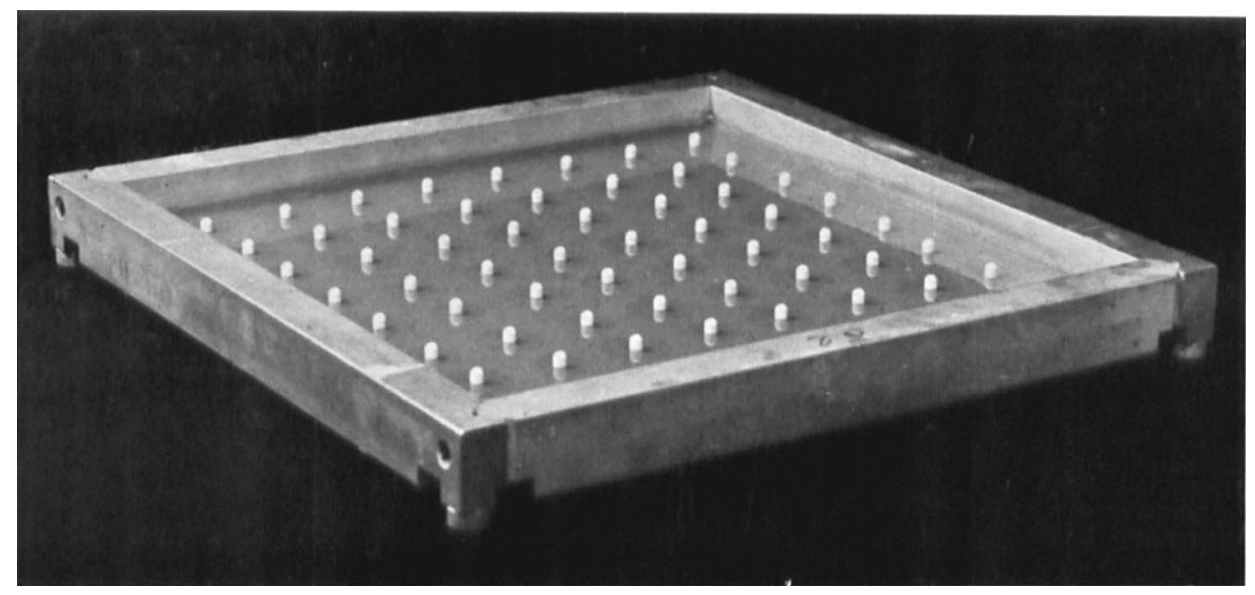

O. Kantorowitz (pp. 357-359)-Antibiotic assay tray. Plate 1 